\title{
The appropriate hybrid surgical strategy in three-level cervical degenerative disc disease: a finite element analysis
}

\author{
Y. M. Xie ${ }^{1 \dagger}$, Y. C. Zheng ${ }^{2 \dagger}$, S. J. Qiu', K. Q. Gong ${ }^{1}$ and Y. Duan ${ }^{1 *}$ (I)
}

\begin{abstract}
Objective: The purpose of this FE study was to analyze the biomechanical characteristics of different HS strategies used in the treatment of three-level CDDD (one-level CDA and two-level ACDF).

Methods: We validated the FE model of an intact cervical spine established by transferring the data, collected by 3D CT scan, to the FE software ABAQUS and comparing these data with the data from published studies. Then, the FE model of hybrid surgery was reconstructed to analyze the range of motion (ROM), facet joint force, and stress distribution on an ultrahigh molecular weight polyethylene (UHMWPE) core.

Results: The current cervical FE model was able to measure the biomechanical changes in a follow-up hybrid surgery simulation. The total ROM of the cervical HS models was substantially decreased compared with the total ROM of the intact group, and the M2 (C3/4 ACDF, C4/5 CDA, and C5/6 ACDF) model had the closest total ROM to the intact group, but the facet joint force adjacent to the treatment levels showed very little difference among them. The stress distribution showed noticeable similarity: two flanks were observed in the center core, but the inlay of $\mathrm{M} 2$ was more vulnerable.
\end{abstract}

Conclusions: Through the comparison of ROM, the facet joint force after CDA, and the stress distribution of the prosthesis, we find that $\mathrm{M} 2$ model has a better theoretical outcome, especially in preserving the maximum total ROM.

Keywords: Three-level cervical degenerative disc disease, Hybrid surgery, Finite element

\section{Background}

Cervical degenerative disc disease (CDDD) has become a common condition causing pain and/or neurological deficit secondary to compression of the nerve roots or spinal cord [1,2]. Anterior cervical discectomy and fusion (ACDF) is a standard surgical procedure for CDDD. This procedure aims to decompress the affected neural components, preserve intradiscal height, and provide mechanical stability [3]. However, an increase in motion, shear strain, and intradiscal pressure in adjacent vertebrae after ACDF has also been reported [4].

\footnotetext{
* Correspondence: Duanyang2011@163.com

${ }^{\dagger}$ Y. M. Xie and Y. C. Zheng contributed equally to this work.

'Department of Spine Surgery, Zhujiang Hospital, Southern Medical

University, No.253 Middle Industrial Road, Haizhu District, Guangzhou 510280,

Guangdong Province, China

Full list of author information is available at the end of the article
}

Cervical disc arthroplasty (CDA) is one of the most carefully studied and documented spinal procedures. CDA has been indicated to be a safe and effective alternative to ACDF. CDA can maintain physiologic motion, restore disc height and some viscoelastic properties, decrease the morbidity of fusion, and allow earlier return to function. In addition, CDA can mitigate the adverse biomechanical changes at adjacent vertebrae and consequently prevent the progression of adjacent segment degeneration (ASD) [5].

Some studies have examined the ability of prostheses to absorb vibrational and impact loads at adjacent segments, but cervical disc prostheses have little ability to provide viscoelastic properties anywhere near those of a normal hydrated disc. Therefore, the approved indication for CDA is restricted to single-level or two-level cervical disc disease. Although one prospective trial

(C) The Author(s). 2019 Open Access This article is distributed under the terms of the Creative Commons Attribution 4.0 International License (http://creativecommons.org/licenses/by/4.0/), which permits unrestricted use, distribution, and 
demonstrated efficacy and safety for three-level CDA, the study was off-label and should be considered experimental [6].

How to address three-level CDDD has become a problem. A novel hybrid surgery (HS) strategy consisting of ACDF and CDA was introduced to treat three-level cervical disease. Barbagallo et al. [7] was the pioneer in choosing the HS strategy for two-level and three-level CDDD. Despite the encouraging clinical outcomes of HS, few biomechanical tests have been used in the past to investigate HS strategies [8], and these strategies have lacked a detailed internal structural response to external loading. It is not yet clear which HS strategy represents the best choice or whether HS could be efficient and beneficial for three-level CDDD.

Mathematical models such as the finite element (FE) method can be applied to discover structural responses to external loading and, more importantly, to establish an internal structural response such as stress to external loading [9]. Although several models of the cervical spine have been demonstrated in recent studies, efforts to analyze the internal response, especially to evaluate three-level HS strategies, are lacking. Therefore, the purpose of this FE study is to target biomechanical analyses of the different HS strategies used in the treatment of three-level CDDD (one-level CDA and two-level ACDF).

\section{Methods}

\section{FE modeling and validation}

The C2-C7 region was reconstructed by a 3D CT scan of the cervical spine of a male subject (age 25, height $178 \mathrm{~cm}$, weight $75 \mathrm{~kg}$ ). The present study was approved by the ethical committee of Southern Medical University. Space intervals of $0.625 \mathrm{~mm}$ were set in the coronal
CT images, and the participant in a neutral, unloaded position. Medical image processing software (Mimics 10.1, Materialise Inc., Belgium) was used to construct the geometry, and the data were later transferred to finite element software (ABAQUS 6.11.1, Simulia Inc., USA) to build the spinal components of the vertebrae using CT images.

The intact FE model consists of six vertebrae $(\mathrm{C} 2, \mathrm{C} 3$, $\mathrm{C} 4, \mathrm{C} 5, \mathrm{C} 6$, and $\mathrm{C} 7)$, five intervertebral discs $(\mathrm{C} 2-\mathrm{C} 3, \mathrm{C} 3-$ $\mathrm{C} 4, \mathrm{C} 4-\mathrm{C} 5$, C5-C6, and $\mathrm{C} 6-\mathrm{C} 7$ ), and all the important components of the cervical spine, such as the cortical bone, cancellous bone, intervertebral discs (consisting of the disc annulus and disc nucleus), and ligaments (Fig. 1). Solid elements were used for modeling vertebral bodies and posterior elements, but the material was described as isotropic. Shell elements were used for the cortical bone of the vertebral body, which is a very thin sheet of bone. A solid tetrahedral element was used for the cancellous part. A layer of shell with a thickness of $0.4 \mathrm{~mm}$ was divided into three regions (including two cartilage endplates and a cortical bone), covering the cancellous bone [10, 11]. To model the facet cartilage, the facet region was extracted from the geometry and enlarged into a solid volume by sweeping with a depth of $0.5 \mathrm{~mm}$ [12]. At a ratio of approximately $6: 4$, the intervertebral space was partitioned into annulus ground substance and the nucleus pulposus. A layer of net-like annulus fibers on the circumferential surface of the substance, which account for $19 \%$ of the volume of the annulus fibrosus, was constructed with an inclination between 15 and $45^{\circ}$ with respect to the transverse plane [13].

Five different ligaments in the cervical spine, whose insertion points were chosen to mimic anatomic observations as closely as possible $[14,15]$, were rebuilt in the
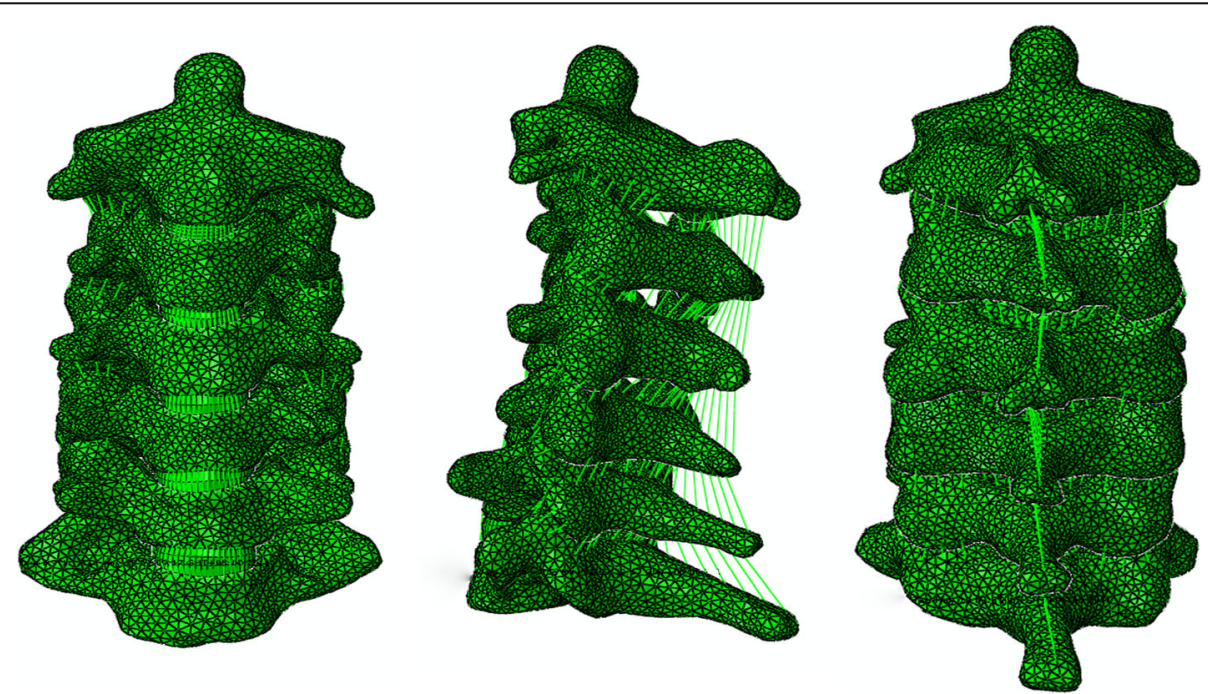

Fig. 1 The intact FE model 
FE models as tension-only nonlinear connectors: the anterior longitudinal ligament (ALL), posterior longitudinal ligament (PLL), spinous ligament (SL), capsular ligament $(\mathrm{CL})$, and ligamentum flavum (LF). Each spinal component represented the most commonly used values collected from the literature [16-20], and the material and mechanical properties are shown in Table 1 and Fig. 2.

With $74 \mathrm{~N}$ of axial compression superior to $\mathrm{C} 2$, static analysis was conducted by imposing $1.8 \mathrm{Nm}$ of flexionextension, lateral bending, and axial rotation movements. With all degrees of freedom constrained, the boundary condition was simulated by fixing the inferior surface of the $\mathrm{C} 7$ vertebra. The movements and the axial pre-compression forces were loaded onto $\mathrm{C} 2$. By using frictionless contact, the facet joints were simulated.

To verify the intact model, a comparison of the predicted results with those reported in the literature was performed.

\section{FE model hybrid surgery simulation}

Based on a validated model of the aforementioned intact $\mathrm{C} 2-\mathrm{C} 7$ model, the data were then imported into the FE software package ABAQUS (v 6. 11.1) to build the surgery simulation models. Our study selected the Mobi-C cervical disc (a mobile-core ADR, LDR Medical, Troyes, France) as the CDA prosthesis, which consists of three components: a mobile-bearing device composed of two titanium plasma-sprayed and hydroxyapatite (HA)coated cobalt-chromium alloy endplates and an ultrahigh molecular weight polyethylene (UHMWPE) mobile insert [21]. The material properties of the $\mathrm{CoCr}$ alloy and UHMWPE obtained from previous literature are also shown in Table 1.

To simulate the surgical procedure as closely as possible, the anterior longitudinal ligament at segments C3C6 was excised. In addition, the annulus of the insertion area was removed by approximately $62 \%$ anteriorly, and the nucleus pulposus was completely removed. In addition, to maximize the bony contact area of Allograft and Mobi-C, the endplate of the CDA segment was partially removed.

Allograft and Mobi-C were implanted into C3/4, C4/5, and $\mathrm{C} 5 / 6$ for the HS models in three alternations. M1:
C3/4 ACDF, C4/5 ACDF, and C5/6 CDA; M2: C3/4 $\mathrm{ACDF}, \mathrm{C} 4 / 5 \mathrm{CDA}$, and C5/6 ACDF; and M3: C3/4 CDA, C4/5 ACDF, and C5/6 ACDF. The models were designed to simulate the mid-long stage postoperatively; thus, the ACDF segments did take into account bone fusion.

\section{Biomechanical comparison}

The same boundary and loading conditions were applied to the HS models. A precompression of $74 \mathrm{~N}$ was imposed on $\mathrm{C} 2$ in all simulations. At a pure moment of $1.8 \mathrm{Nm}$ in all directions (flexion-extension, lateral bending, and axial rotation), the simulations were run for each model. The ROM was measured in the intact model and the HS models. Facet joint force and stress distribution in the Mobi-C prosthesis were compared among the different types of HS.

\section{Results}

\section{FE model validation}

The final intact model consisted of 130,429 elements and 30,181 nodes. Figure 3 shows the details of the previous data used in the comparison. The figure summarizes the comparison of the intersegmental responses between the intact model and previously published data under combined flexion-extension, lateral bending, and axial rotation conditions. All the predicted responses were well paired with the published data reported in previous studies [22-24]. Therefore, the current cervical FE model was able to demonstrate the biomechanical changes in a follow-up hybrid surgery simulation.

\section{FE model surgery simulation}

Figure 4 illustrates the surgery-simulated FE models with one-level CDA and two-level ACDF. In the present study, Allograft and Mobi-C were implanted into arranged intervertebral spaces, which were assumed to be fully integrated. Their bone-bone or bone-prosthesis surfaces were simulated by imposing an ideal, rough behavior, thus preventing mobility.

Table 1 Material and mechanical properties of different parts used in the finite element model

\begin{tabular}{llll}
\hline Component & Young's modulus (MPa) & Poisson's ratio & Element type \\
\hline Cortical bone and endplate & $12,000.0$ & 0.3 & Triangular shell element \\
Cancellous bone & 100.0 & 0.25 & Tetrahedral element \\
Disc annulus & 3.4 & 0.4 & Hexahedral element \\
Disc nucleus & 1.0 & 0.49 & Hexahedral element \\
CoCr alloy & $210,000.0$ & 0.3 & Tetrahedral element \\
UHMWPE & 3000.0 & 0.3 & Tetrahedral element \\
Ligament & Nonlinear tension only connector & & \\
\hline
\end{tabular}




\section{BIOMECHANICAL CHANGE OF LIGAMENT (C3-C5)}

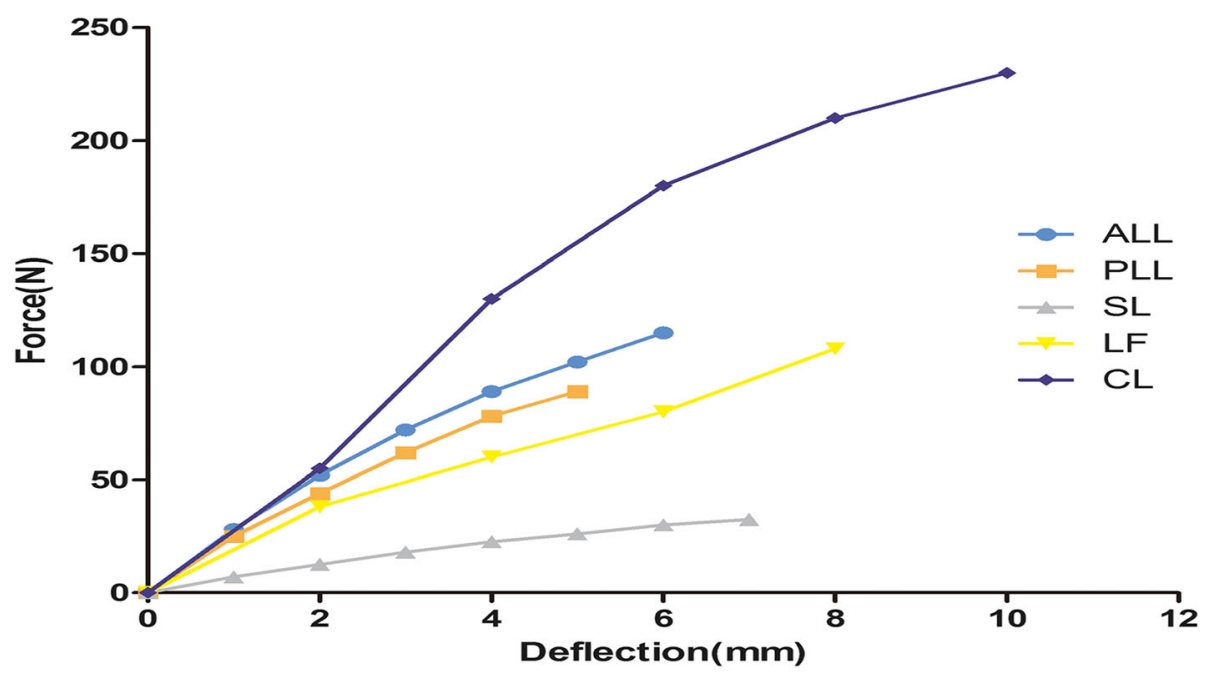

BIOM ECHANICAL CHANGE OF LIGAMENT (C6-C7)

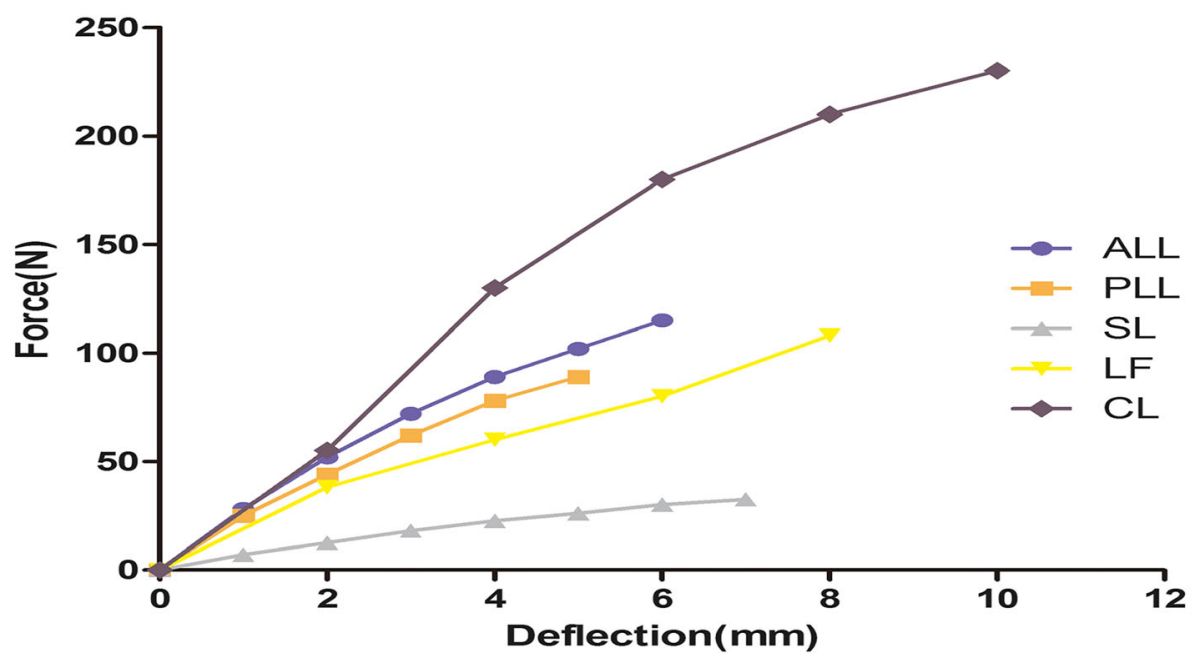

Fig. 2 Biomechanical change of ligament (C3-C7)

\section{Intersegmental and total ROM analyses}

Compared to that in the normal model, the intersegmental ROM of the $\mathrm{C} 2 / 3$ and C6/7 segments after hybrid surgery showed no noticeable differences, as presented in Fig. 4. However, the intersegmental ROM of the arranged CDA segments had noticeable differences compared to the previous intersegmental ROM.

Under flexion-extension, lateral bending, and axial rotation conditions, the total ROM of the intact and surgery-simulated FE models showed noticeable differences, which have important clinical significance. In the present study, the total ROM of the cervical HS models was substantially decreased compared with that of the intact group. However, the M2 model had the closest total ROM to the intact group, especially under flexionextension and axial rotation conditions (Fig. 5).

\section{Facet joint force analyses}

The facet joint force was measured at each segment. The facet joint force adjacent to the treatment levels $(\mathrm{C} 2 / 3, \mathrm{C6} / 7)$ showed very little difference among the three HS groups compared with the intact group. However, the facet joint force at CDA segments was different at the corresponding segments in the intact cervical spine model (Fig. 6). As the histogram clearly shows, the facet joint force of CDA levels increased to some extent. The maximum increased range of facet joint force was measured under flexion conditions. The face joint force 

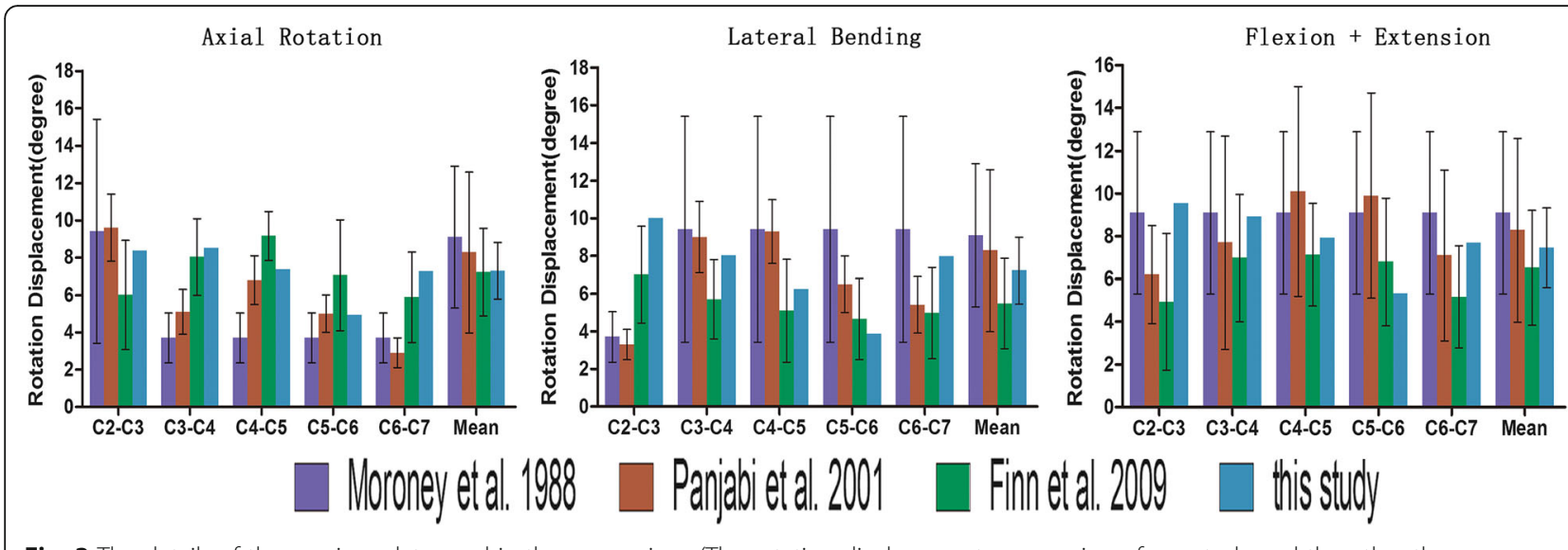

Fig. 3 The details of the previous data used in the comparison (The rotation displacement comparsion of our study and the other three published studies)

at the CDA segment of the HS models increased 3.3fold in M1, 3.2-fold in M2, and 3.4-fold in M3, corresponding to the segment of the intact model. The maximal value of the facet joint force was obtained under extension conditions. The facet joint force was $121.43 \mathrm{~N}$ at the C5/6 segment in M1, $120.30 \mathrm{~N}$ at the $\mathrm{C} 4 / 5$ segment in $\mathrm{M} 2$, and $130.7 \mathrm{~N}$ at the $\mathrm{C} 3 / 4$ segment in M3.

\section{Stress distribution on the UHMWPE core}

The stress distribution located at each CDA segment in the HS models is presented in Fig. 7. Under flexion-extension, lateral bending, and axial rotation conditions, the stress distribution of the UHMWPE cores showed noticeable similarity, and the distribution was two flanks from the center core. The maximal value of stress was $11.6 \mathrm{MPa}$ at the $\mathrm{C} 5 / 6$ segment in $\mathrm{M} 1,30.44 \mathrm{MPa}$ at the $\mathrm{C} 4 / 5$ segment in $\mathrm{M} 2$, and $14.4 \mathrm{MPa}$ at the $\mathrm{C} 3 / 4$ segment in M3.

\section{Discussion}

Three-level CDDD is common in clinical practice [25], but surgeons are occasionally confronted with a patient requiring surgical treatment due to CDDD, involving multiple levels. Because of a paucity of data regarding three-level CDDD, the optimal management of this disorder remains controversial and case dependent. While ACDF has long been advocated for three-level CDDD, there is evidence supporting more substantial biomechanical effects in three-level fusion [26, 27]. The anterior approach may have a little more trauma than the posterior approach. There are still some annoying complications with the posterior approach such as axial pain and concomitant cervical kyphosis without fixation. The
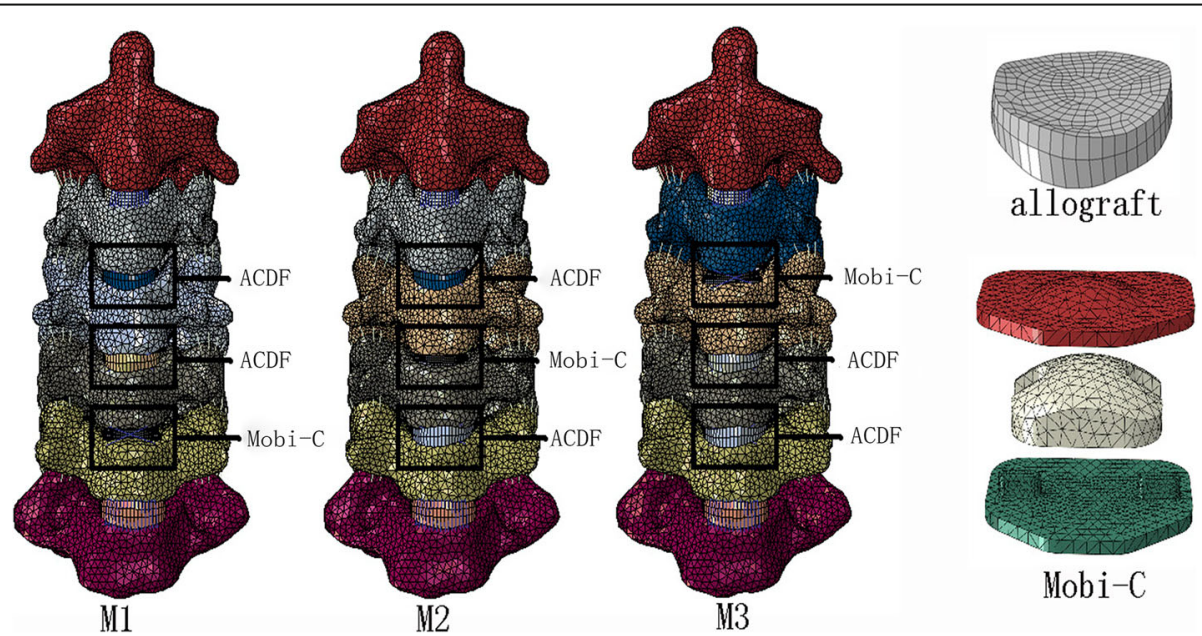

Mobi-C

Fig. 4 FE models with one-level CDA and two-level ACDF 

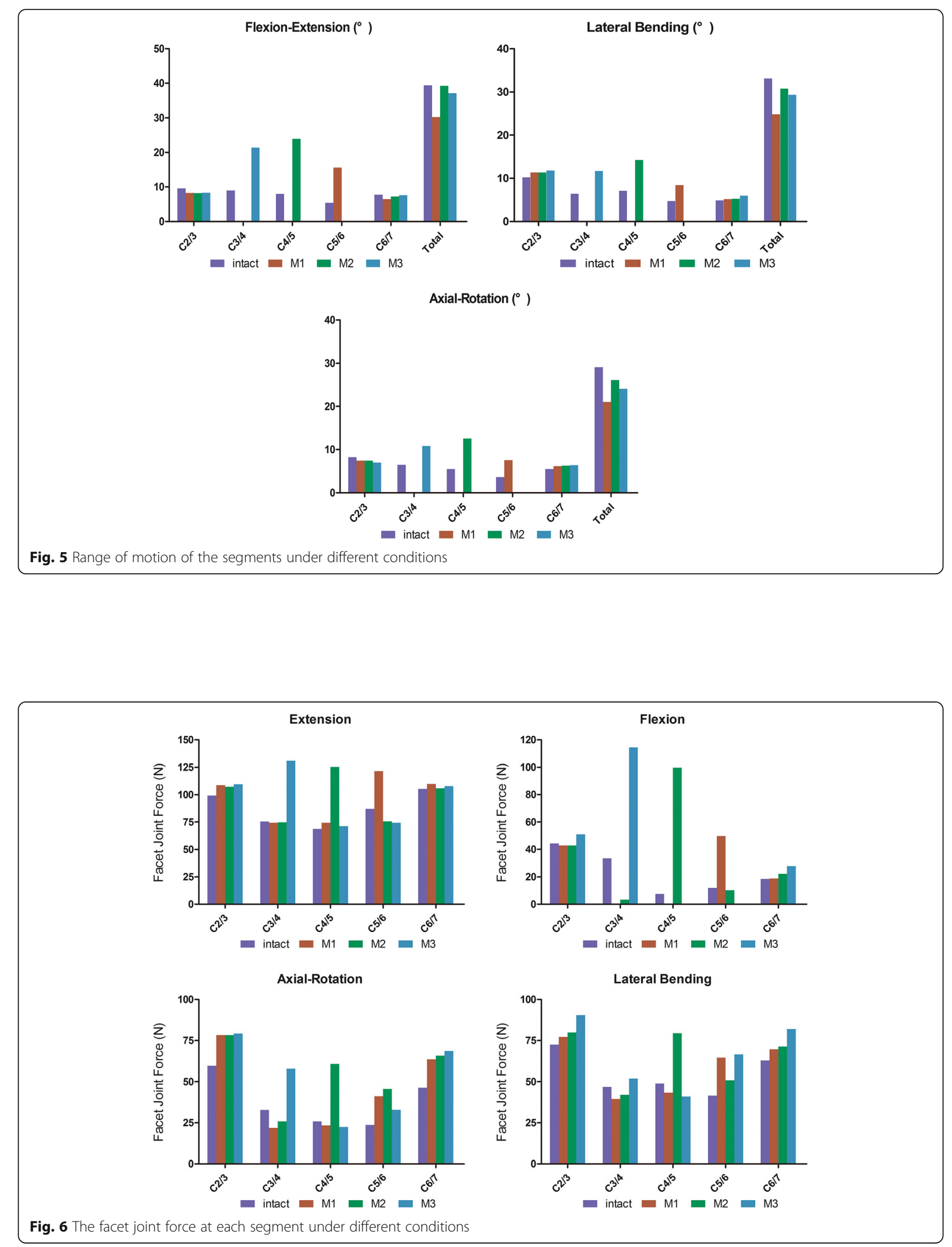


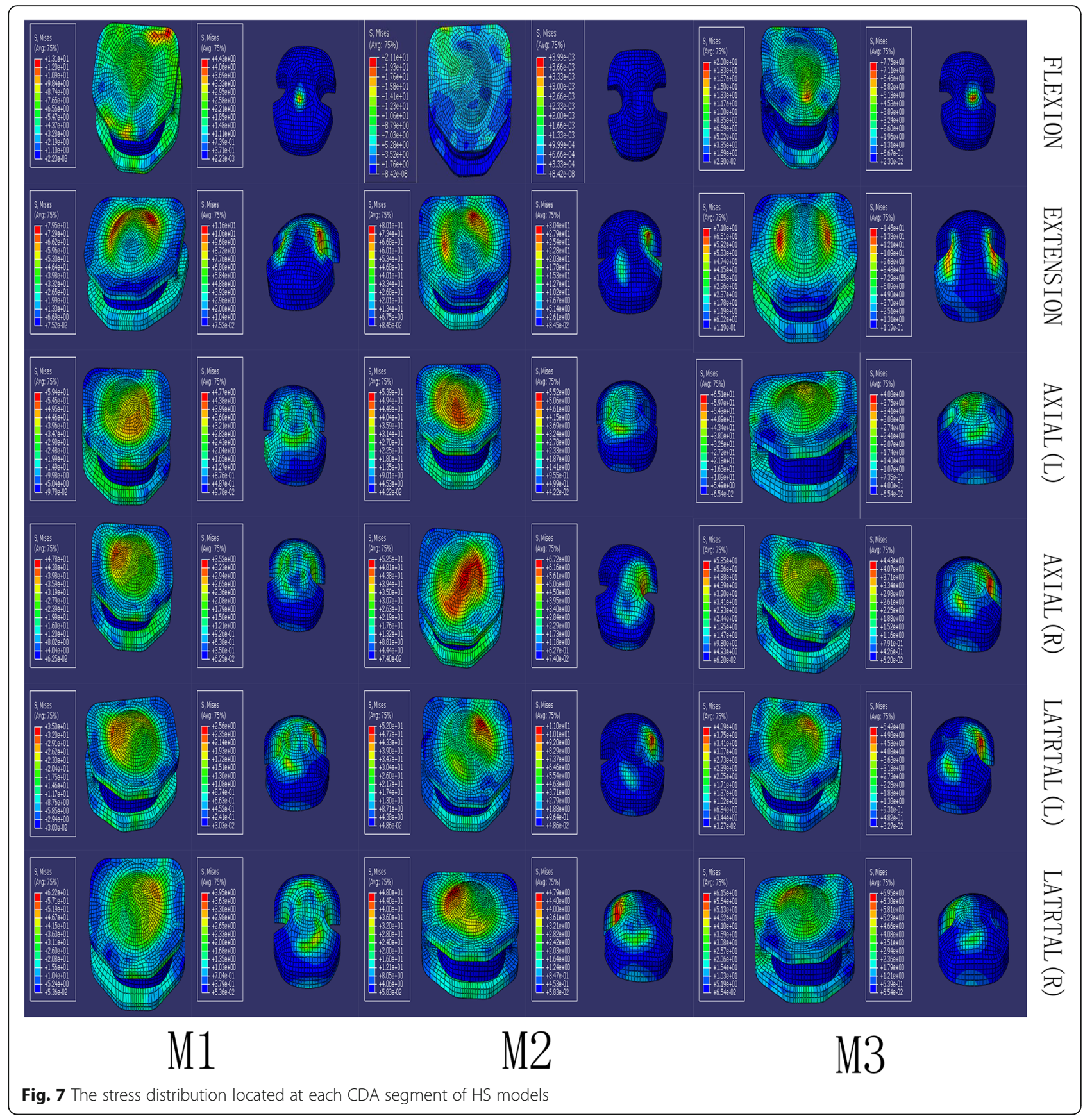

degree of degeneration in different levels is much variant among patients, some levels in some patients are still fit for arthroplasty surgery. HS strategy is a combination of replacement and fusion operation that can reduce the fusion segment and thus reach the goal of retaining as much ROM as possible, reducing the stress between the adjacent intervertebral disc and decreasing the unfusion rate.

To assess the ROM after three-level HS to find out how much ROM we can retain compares to the intact model, we chose to compare HS with intact cervical spine, because all degrees of freedom of $\mathrm{C} 7$ is constrained by the relative fixing inferior surface of the $\mathrm{C} 7$ vertebra. If the replacement segment is located at C6/7, it might affect the data. We should choose the segments of $\mathrm{C} 3 / 4-\mathrm{C} 5 / 6$ rather than $\mathrm{C} 4 / 5-\mathrm{C} 6 / 7$. In the present study, the ROM of segments $\mathrm{C} 2 / 3$ and $\mathrm{C} 6 / 7$ in the HS models confirmed an interesting phenomenon. The results indicated that there were no significant ROM changes in the segment adjacent to the operative segments compared to the intact group. Under flexionextension, lateral bending, and axial torsion conditions, 
the total ROM of the HS models decreased to some extent in the present study. This result is consistent with the results from a study by Cho et al. [28]; the use of a cadaveric biomechanical test showed that two-level ACDF could decrease the entire ROM, and two-level CDA and hybrid ACDF/CDA did not show significant changes in the adjacent-level ROM. However, our study showed an encouraging result in that the M2 model had the closest total ROM to the intact group, especially under flexion-extension and axial torsion conditions. In this regard, the results of this study may indicate how to choose an optimal HS strategy in terms of preserving the maximum total ROM.

The increased ROM found at the CDA segments is probably caused by the excision of the ALL and the anterior parts of the annulus. Furthermore, the increased ROM may have resulted in increased stress of the facet joint force in the implanted segment [29]. An increase in the facet joint force after CDA was reported to accelerate degeneration in implanted segments [30], and subsequent alterations in cervical spine biomechanics result in hypertrophy of the ligamentum flavum and facet joint laxity. Some studies have indicated that the increased facet joint force in implanted segments might lead to the degeneration of new segments [31]. Lee et al. [20] analyzed the biomechanical changes in Mobi-C after CDA. The ROM in the CDA segment increased during flexion (33\%), extension (56\%), lateral bending (35\%), and axial torsion (105\%). The facet joint force increased by $210 \%$ in both fixed and mobile core models. In our study, the facet joint force at the CDA segments was different from the force at the corresponding segments in the intact cervical spine model. As the histogram clearly shows, the facet joint force of the CDA segments increased to some extent. However, the facet joint force adjacent to the treatment levels $(\mathrm{C} 2 / 3, \mathrm{C} 6 / 7)$ was hardly different among the HS groups compared with the intact group. Based on the results described above, we believe that his procedure has no adverse effect on the facet joints of adjacent segments but on the facet joints before operation due to the increase in the facet joint force after CDA, which may be regarded as a risk factor that leads to new segment degeneration.

Over the last decade, some cervical devices have gained US Food and Drug Administration (FDA) approval [32]. We classified the cervical devices as constrained or mobile types according to the type of prosthesis implanted. Mobi-C belongs to the mobile type of devices; despite the fact that its insertion point slightly misses the center, it tends to have a biomechanical impact on the facet joint because the UHMWPE core of the prosthesis is translocated, while the pressure on the facet joint is high [33]. Our result is also in agreement with the results of the study mentioned above, showing increased pressure on the UHMWPE core in Mobi-C with a mobile core. However, our study showed that the maximal force value of the UHMWPE core was increased in the M2 strategy compared with the HS strategies. This finding indicates that the UHMWPE core may wear easily in the M2 strategy.

The present study, focusing on the changes in the ROM, facet joint force, and UHMWPE core, aimed to analyze the biomechanical performance after three-level HS. The conclusions are summarized as follows: (1) HS does not affect the ROM or facet joint force of the adjacent segment in the prevention of ASD, (2) the results of total ROM show that the M2 strategy is the best HS strategy in terms of preserving the maximum total ROM, (3) the ROM and the facet joint force in the CDA segments clearly increase, and (4) the maximal force value of the UHMWPE core is increased in the M2 strategy compared with the other strategies.

\section{Conclusion}

In our study, we try to find the best theoretical combination in these three models by analyzing the FE simulation. As the discussion above, through the comparison of ROM, the facet joint force after CDA, and the stress distribution of the prosthesis, we find that M2 model has a better theoretical outcome, especially in preserving the maximum total ROM. In clinical practice, we choose the hybrid surgery according to the strict surgical indications. If patients can be unconstrained to choose all the three combinations, M2 is recommended according to our theoretical results. If the replacement segment is the exclusive selection, we should choose the corresponding combination.

\section{Limitation}

In the study, there are still several limitations. Though we have conducted some research about the cervical three-level HS simulation, there are much further improvements that shall be carried out. First, if the EF model can include the entire spine and surrounding muscles, the biomechanical simulation of the entire model will be greatly improved. The additional soft tissues such as muscles can imitate the dynamic effect of the active and passive contraction that might make our work much more integrated and authentic. Second, the EF model only reflects the biomechanical state of a particular time period and cannot reflect the continuous dynamic and biomechanical state of the whole time period. Finally, the results of the EF research can only theoretically support the researchers' hypothesis, and the reliability of the results will ultimately need to be confirmed by cadaver specimens and clinical studies. 


\section{Abbreviations}

3D: Three-dimensional; ACDF: Anterior cervical discectomy and fusion; ALL: Anterior longitudinal ligament; ASD: Adjacent segment degeneration; CDA: Cervical disc arthroplasty; CDDD: Cervical degenerative disc disease; CL: Capsular ligament; CT: Computed tomography; FE: Finite element; HA: Hydroxyapatite; HS: Hybrid surgery; LF: Ligamentum flavum; PLL: Posterior longitudinal ligament; ROM: Range of motion; SL: Spinous ligament; UHMWPE: Ultra-high molecular weight polyethylene

\section{Acknowledgements}

The authors acknowledged that YM and YC participated in the study as the first authors and contributed equally.

\section{Authors' contributions}

YD designed the study and analyzed the data. SJ and KQ collected the data and helped in analyzing the data. YM and YC participated in the design of the study, the analysis of the data, and writing of the manuscript. All authors have read and approved the final manuscript and agreed with the contributions mentioned above.

\section{Funding}

Not applicable

\section{Availability of data and materials}

The datasets generated and/or analyzed during the current study are available from the corresponding author on reasonable request.

\section{Ethics approval and consent to participate}

The participant had signed an informed consent, and the study was approved by the ethical committee of Southern Medical University.

\section{Consent for publication}

We have obtained consent signed by the participants to publish.

\section{Competing interests}

The authors declare that they have no competing interests.

\section{Author details}

'Department of Spine Surgery, Zhujiang Hospital, Southern Medical University, No.253 Middle Industrial Road, Haizhu District, Guangzhou 510280 Guangdong Province, China. ${ }^{2}$ Department of Spine Surgery, The Second People's Hospital of Shenzhen, Shenzhen 518037, Guangdong, China.

\section{Received: 25 August 2019 Accepted: 28 November 2019}

\section{Published online: 16 December 2019}

\section{References}

1. Gibson J, Nouri A, Krueger B, Lakomkin N, Nasser R, Gimbel D, Cheng J. Degenerative cervical myelopathy: a clinical review. Yale J Biol Med. 2018;91:43-8.

2. Schoenfeld AJ, George AA, Bader JO, Caram PM Jr. Incidence and epidemiology of cervical radiculopathy in the United States military: 2000 to 2009. J Spinal Disord Tech. 2012;25:17-22. https://doi.org/10.1097/BSD. Ob013e31820d77ea.

3. Jackson RJ, Davis RJ, Hoffman GA, Bae HW, Hisey MS, Kim KD, Gaede SE, Nunley PD. Subsequent surgery rates after cervical total disc replacement using a Mobi-C Cervical Disc Prosthesis versus anterior cervical discectomy and fusion: a prospective randomized clinical trial with 5-year follow-up. J Neurosurg Spine. 2016;24:734-45. https://doi.org/10.3171/2015.8.Spine15219.

4. Elsawaf A, Mastronardi L, Roperto R, Bozzao A, Caroli M, Ferrante L. Effect of cervical dynamics on adjacent segment degeneration after anterior cervical fusion with cages. Neurosurg Rev. 2009;32:215-24; discussion 224. https:// doi.org/10.1007/s10143-008-0164-2.

5. Turel MK, Kerolus MG, Adogwa O, Traynelis VC. Cervical arthroplasty: what does the labeling say? Neurosurg Focus. 2017;42:E2. https://doi.org/10.3171/ 2016.11.Focus 16414

6. Laratta JL, Shillingford JN, Saifi C, Riew KD. Cervical disC arthroplasty: a comprehensive review of single-level, multilevel, and hybrid procedures. Glob Spine J. 2018;8:78-83. https://doi.org/10.1177/2192568217701095.

7. Barbagallo GM, Assietti R, Corbino L, Olindo G, Foti PV, Russo V, Albanese V. Early results and review of the literature of a novel hybrid surgical technique combining cervical arthrodesis and disc arthroplasty for treating multilevel degenerative disc disease: opposite or complementary techniques? Eur Spine J. 2009;18(Suppl 1):29-39. https://doi.org/10.1007/ s00586-009-0978-9.

8. Mo Z, Li Q, Jia Z, Yang J, Wong DW, Fan Y. Biomechanical consideration of prosthesis selection in hybrid surgery for bi-level cervical disc degenerative diseases. Eur Spine J. 2017;26:1181-90. https://doi.org/10.1007/s00586-0164777-9.

9. Wheeldon JA, Pintar FA, Knowles S, Yoganandan N. Experimental flexion/ extension data corridors for validation of finite element models of the young, normal cervical spine. J Biomech. 2006;39:375-80. https://doi.org/10. 1016/j.jbiomech.2004.11.014

10. Eswaran SK, Gupta A, Adams MF, Keaveny TM. Cortical and trabecular load sharing in the human vertebral body. J Bone Miner Res. 2006;21:307-14. https://doi.org/10.1359/jbmr.2006.21.2.307.

11. Hernandez CJ, Gupta A, Keaveny TM. A biomechanical analysis of the effects of resorption cavities on cancellous bone strength. J Bone Miner Res. 2006; 21:1248-55. https://doi.org/10.1359/jbmr.060514.

12. Yoganandan N, Knowles SA, Maiman DJ, Pintar FA. Anatomic study of the morphology of human cervical facet joint. Spine (Phila Pa 1976). 2003;28: 2317-23. https://doi.org/10.1097/01.Brs.0000085356.89103.A5.

13. Denoziere G, Ku DN. Biomechanical comparison between fusion of two vertebrae and implantation of an artificial intervertebral disc. J Biomech. 2006;39:766-75. https://doi.org/10.1016/j.jbiomech.2004.07.039.

14. Kumaresan S, Yoganandan N, Pintar FA. Finite element analysis of the cervical spine: a material property sensitivity study. Clin Biomech (Bristol, Avon). 1999;14:41-53.

15. Yoganandan N, Kumaresan S, Pintar FA. Geometric and mechanical properties of human cervical spine ligaments. J Biomech Eng. 2000;122:623-9.

16. Goel VK, Clausen JD. Prediction of load sharing among spinal components of a C5-C6 motion segment using the finite element approach. Spine (Phila Pa 1976). 1998;23:684-91.

17. Clausen JD, Goel VK, Traynelis VC, Scifert J. Uncinate processes and Luschka joints influence the biomechanics of the cervical spine: quantification using a finite element model of the C5-C6 segment. J Orthop Res. 1997;15:342-7. https://doi.org/10.1002/jor.1100150305.

18. Yoganandan N, Kumaresan SC, Voo L, Pintar FA, Larson SJ. Finite element modeling of the C4-C6 cervical spine unit. Med Eng Phys. 1996;18:569-74.

19. Yoganandan N, Kumaresan S, Pintar FA. Biomechanics of the cervical spine part 2. Cervical spine soft tissue responses and biomechanical modeling. Clin Biomech (Bristol, Avon). 2001;16:1-27.

20. Lee SH, Im YJ, Kim KT, Kim YH, Park WM, Kim K. Comparison of cervical spine biomechanics after fixed- and mobile-core artificial disc replacement: a finite element analysis. Spine (Phila Pa 1976). 2011;36:700-8. https://doi. org/10.1097/BRS.0b013e3181f5cb87.

21. Hisey MS, Bae HW, Davis R, Gaede S, Hoffman G, Kim K, Nunley PD, Peterson D, Rashbaum R, Stokes J. Multi-center, prospective, randomized, controlled investigational device exemption clinical trial comparing Mobi-C Cervical Artificial Disc to anterior discectomy and fusion in the treatment of symptomatic degenerative disc disease in the cervical spine. Int J Spine Surg. 2014;8. https://doi.org/10.14444/1007.

22. Moroney SP, Schultz AB, Miller JA, Andersson GB, Load-displacement properties of lower cervical spine motion segments. J Biomech. 1988:21:769-79.

23. Panjabi MM, Crisco JJ, Vasavada A, Oda T, Cholewicki J, Nibu K, Shin E. Mechanical properties of the human cervical spine as shown by threedimensional load-displacement curves. Spine (Phila Pa 1976). 2001;26:2692-700

24. Finn MA, Brodke DS, Daubs M, Patel A, Bachus KN. Local and global subaxial cervical spine biomechanics after single-level fusion or cervical arthroplasty. Eur Spine J. 2009;18:1520-7. https://doi.org/10.1007/s00586-009-1085-7.

25. Northover JR, Wild JB, Braybrooke J, Blanco J. The epidemiology of cervical spondylotic myelopathy. Skelet Radiol. 2012;41:1543-6. https://doi.org/10. 1007/s00256-012-1388-3

26. Chang UK, Kim DH, Lee MC, Willenberg R, Kim SH, Lim J. Changes in adjacent-level disc pressure and facet joint force after cervical arthroplasty compared with cervical discectomy and fusion. J Neurosurg Spine. 2007;7:33-9. https://doi.org/10.3171/spi-07/07/033.

27. Park J, Shin JJ, Lim J. Biomechanical analysis of disc pressure and facet contact force after simulated two-level cervical surgeries (fusion and 
arthroplasty) and hybrid surgery. World Neurosurg. 2014;82:1388-93. https://doi.org/10.1016/j.wneu.2014.06.013.

28. Cho BY, Lim J, Sim HB, Park J. Biomechanical analysis of the range of motion after placement of a two-level cervical ProDisc-C versus hybrid construct. Spine (Phila Pa 1976). 2010;35:1769-76. https://doi.org/10.1097/ BRS.0b013e3181c225fa.

29. Brenke C, Scharf J, Schmieder K, Barth M. High prevalence of heterotopic ossification after cervical disc arthroplasty: outcome and intraoperative findings following explantation of 22 cervical disc prostheses. J Neurosurg Spine. 2012;17:141-6. https://doi.org/10.3171/2012.4.Spine12223.

30. Auerbach JD, Jones KJ, Fras Cl, Balderston JR, Rushton SA, Chin KR. The prevalence of indications and contraindications to cervical total disc replacement. Spine J. 2008;8:711-6. https://doi.org/10.1016/j.spinee.2007.06. 018.

31. Rundell SA, Auerbach JD, Balderston RA, Kurtz SM. Total disc replacement positioning affects facet contact forces and vertebral body strains. Spine (Phila Pa 1976). 2008:33:2510-7. https://doi.org/10.1097/BRS. 0b013e318186b258.

32. Sasso WR, Smucker JD, Sasso MP, Sasso RC. Long-term clinical outcomes of cervical disc arthroplasty: a prospective, randomized, controlled trial. Spine (Phila Pa 1976). 2017;42:209-16. https://doi.org/10.1097/brs. 0000000000001746.

33. Rousseau MA, Bradford DS, Bertagnoli R, Hu SS, Lotz JC. Disc arthroplasty design influences intervertebral kinematics and facet forces. Spine J. 2006;6:258-66. https://doi.org/10.1016/j.spinee.2005.07.004.

\section{Publisher's Note}

Springer Nature remains neutral with regard to jurisdictional claims in published maps and institutional affiliations.

Ready to submit your research? Choose BMC and benefit from:

- fast, convenient online submission

- thorough peer review by experienced researchers in your field

- rapid publication on acceptance

- support for research data, including large and complex data types

- gold Open Access which fosters wider collaboration and increased citations

- maximum visibility for your research: over $100 \mathrm{M}$ website views per year

At $\mathrm{BMC}$, research is always in progress.

Learn more biomedcentral.com/submissions 